\title{
Clinical characteristics and prognosis of patients with renal cell carcinoma and liver metastasis
}

\author{
SHINSUKE HAMADA, KEIICHI ITO, KENJI KURODA, AKINORI SATO, JUNICHI ASAKUMA, \\ AKIO HORIGUCHI, KENJI SEGUCHI and TOMOHIKO ASANO
}

Department of Urology, National Defense Medical College, Tokorozawa, Saitama 3598513, Japan

Received August 4, 2014; Accepted September 10, 2014

DOI: $10.3892 / \mathrm{mco} .2014 .432$

\begin{abstract}
The prognosis of patients with renal cell carcinoma (RCC) and liver metastasis (LM) is poor. We evaluated the clinical characteristics, prognosis and prognostic factors of RCC patients with LM. A total of 25 patients who underwent radical or partial nephrectomy (Nx) for RCC between November, 1980 and April, 2013 at the National Defense Medical College, Tokorozawa, Saitama, Japan, with LM at initial presentation or following $\mathrm{Nx}$, were included in this study. The association between prognosis following development of LM and clinicopathological parameters was analyzed. The Cox proportional hazards regression model was used to identify prognostic predictors. The median cancer-specific survival (CSS) following LM diagnosis was 10.6 months. The presence of sarcomatoid differentiation, Eastern Cooperative Oncology Group performance status (ECOG PS) $\geq 2$, C-reactive protein $\geq 1.0 \mathrm{mg} / \mathrm{dl}$, corrected calcium $\geq 10 \mathrm{mg} / \mathrm{dl}$ and presence of multiple organ metastases, were identified as CSS predictors. The multivariate analysis identified ECOG PS $\geq 2$ as an independent CSS predictor. Nine patients survived for $>20$ months following LM diagnosis and 1 patient, who received treatment with tyrosine kinase inhibitors (TKIs) for LM, exhibited stable disease for 5 years. Nine patients underwent local LM treatment. Two patients, who underwent hepatic resection, survived for 55.1 and 22 months, respectively. In conclusion, RCC patients with LM may benefit from local LM treatment if they have a limited number of metastases in addition to LM and if their ECOG PS is satisfactory. Indeed, a proportion of RCC patients with LM benefit from TKI therapy. Furthermore, RCC patients with LM and ECOG PS $\geq 2$ apparently have a poor prognosis, regardless of local or systemic therapies.
\end{abstract}

Correspondence to: Dr Shinsuke Hamada, Department of Urology, National Defense Medical College, 3-2 Namiki, Tokorozawa, Saitama 3598513, Japan

E-mail: shinsukehamaji@yahoo.co.jp

Key words: renal cell carcinoma, liver metastasis, prognosis, local treatment, tyrosine kinase inhibitor

\section{Introduction}

Approximately $30 \%$ of patients with renal cell carcinoma (RCC) exhibit distant metastasis at initial presentation, whereas a further $30 \%$ of the patients develop metastases following nephrectomy (Nx) (1). RCC patients develop metastases at various sites, including the lungs, lymph nodes, bone, brain and liver and their prognosis depends on the metastatic site. The frequency of liver metastasis (LM) in RCC patients is lower compared to that of metastasis to other sites, such as the lungs, lymph nodes and bone. The rate of LM was reported to be $9.3-18 \%$ (2-5). The prognosis of RCC patients with LM is poor and the median overall survival is 7.6-12 months, which is shorter compared to that of patients with metastasis to other sites (2-4). Patients with metastatic RCC were treated with interferon and/or interleukin-2 during the cytokine era; however, the response rate to cytokine therapy was reportedly only $10-20 \%$ (4). Cytokine therapy was occasionally effective for lung or lymph node metastases; however, it was generally not effective for liver, brain and bone metastases. Local treatments are reportedly effective in certain RCC patients with bone and brain metastases $(6,7)$. Combination therapy with radiation and zoledronic acid was shown to decrease the rate of skeletal-related events in RCC patients; reossification was also reported in some patients (8). $\gamma$-knife surgery achieves good local control of brain metastasis from RCC. This procedure improves peritumoral edema and the survival rate of patients with multiple brain metastases $(6,9)$. A definitive treatment for LM in RCC patients, however, has not been established. At present, tyrosine kinase inhibitors (TKIs) are used to treat metastatic RCC and the response is expected to be adequate when TKIs are used for organ metastases such as LM and brain metastases, which are considered to be extremely refractory to cytokine therapy $(10,11)$. LM from RCC may grow rapidly and become life-threatening. Local treatments for LM may be beneficial for RCC patients. Long-term survival following surgical resection of a solitary LM was reported in RCC patients $(12,13)$, although the efficacy of local treatments, such as surgical resection, radiofrequency ablation and transarterial embolization, was not fully evaluated. To the best of our knowledge, the number of studies focusing on the treatment of LM from RCC is currently limited.

In the present study, we evaluated the clinical characteristics, prognosis and prognostic factors in RCC patients with LM. We also aimed to determine the characteristics of RCC 
Table I. Clinicopathological characteristics of 25 patients with liver metastasis (LM).

\begin{tabular}{lc}
\hline Variables & Values, mean \pm SD \\
\hline Gender & \\
Male & 21 \\
Female & 4
\end{tabular}

Age at Nx, years (range)

$59.4 \pm 12.4(30-77)$

Age at diagnosis of LM, years (range)

Tumor side ${ }^{\mathrm{a}}$

Right

Left

Tumor size ${ }^{\mathrm{a}}, \mathrm{cm}$ (range)

Cell type ${ }^{a}$

Clear cell

Chromophobe

Histological grade ${ }^{a}$<smiles>[TlH]</smiles>

2

3

Fuhrman grade ${ }^{a}$$$
1
$$$$
2
$$$$
3
$$

4

NA

\section{pT stage ${ }^{a}$}

$1 \mathrm{a}$

$1 \mathrm{~b}$

$2 \mathrm{a}$

$2 b$

$3 a$

$3 \mathrm{~b}$

$3 \mathrm{c}$

4

$\mathrm{MVI}^{\mathrm{a}}$

$+$

-

Tumor necrosis ${ }^{\mathrm{a}}$

$+$

$-$

No. of $\mathrm{LM}^{\mathrm{b}}$

Solitary

Multiple

NA

\section{ECOG PS ${ }^{\mathrm{b}}$}

0

1

2

3

4

NA

Hemoglobin $^{\mathrm{b}}$, g/dl (range)

Platelet count ${ }^{\mathrm{b}}, \mathrm{x} 10^{4} / \mathrm{mm}^{3}$ (range)
Table I. Continued.

\begin{tabular}{lc}
\hline Variables & Values, mean \pm SD \\
\hline $\mathrm{CRP}^{\mathrm{b}}, \mathrm{mg} / \mathrm{dl}$ (range) & $6.8 \pm 8.3(0.3-28)$ \\
$\mathrm{LDH}^{\mathrm{b}}, \mathrm{IU} / \mathrm{l}$ (range) & $323.9 \pm 286.3(110-1,138)$ \\
Corrected calcium $^{\mathrm{b}}, \mathrm{mg} / \mathrm{dl}$ (range) & $8.6 \pm 3.4(8.4-12.7)$ \\
\hline
\end{tabular}

${ }^{\text {a Primary lesion. }}{ }^{\mathrm{b}}$ At the diagnosis of LM. SD, standard deviation. Nx, nephrectomy; NA, not available; MVI, microvascular invasion; ECOG PS, Eastern Cooperative Oncology Group performance status; CRP, C-reactive protein; LDH, lactate dehydrogenase.

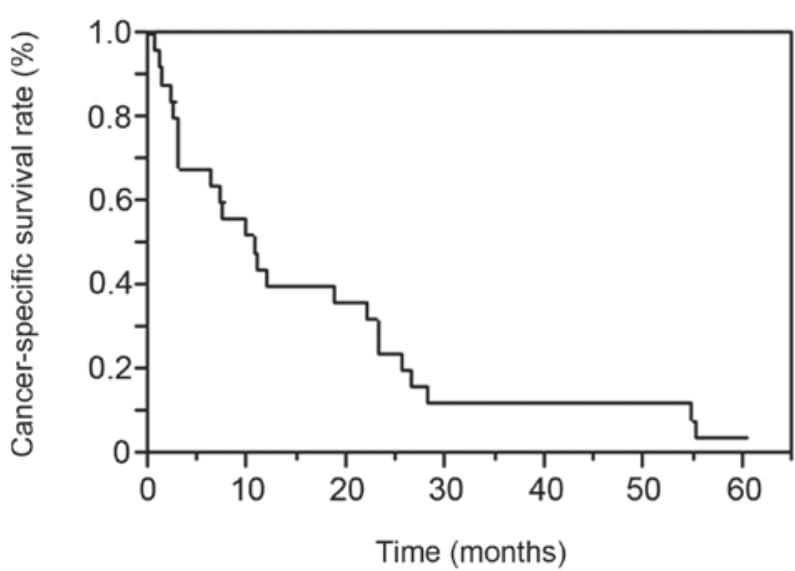

Figure 1. Cancer-specific survival of 25 patients with liver metastasis from renal cell carcinoma. The Kaplan-Meier method revealed 1-, 2- and 3-year survival rates of 40,24 and $12 \%$, respectively.

patients with LM who survived over a relatively long period, with particular focus on the clinical results of local treatments for RCC with LM.

\section{Materials and methods}

Patients and design. We retrospectively reviewed the records of all the patients who underwent radical nephrectomy $(\mathrm{RNx})$ or partial Nx for RCC between November, 1980 and April, 2013 at the National Defense Medical College, Tokorozawa, Saitama, Japan. Our cohort included 25 patients (21 men and 4 women; age at $\mathrm{Nx}, 59.4 \pm 12.4$ years; range, 30-77 years) with LM at initial presentation or who developed LM following Nx. The clinicopathological factors were assessed for each patient using the patient database or clinical records. The factors evaluated included gender, age, treatment after LM presentation, Eastern Cooperative Oncology Group performance status (ECOG PS), histological characteristics, tumor grade, Fuhrman grade, microvascular invasion, histological tumor necrosis, sarcomatoid differentiation and biochemical parameters, such as hemoglobin level, platelet count, lactate dehydrogenase level, corrected calcium $(\mathrm{Ca})$ level and $\mathrm{C}$-reactive protein (CRP) level. All 25 patients underwent RNx. Local recurrence and metastases were monitored by postoperative examination of each patient every 3-6 months for the first 5 years and every 6-12 months thereafter. The follow-up included physical 
A

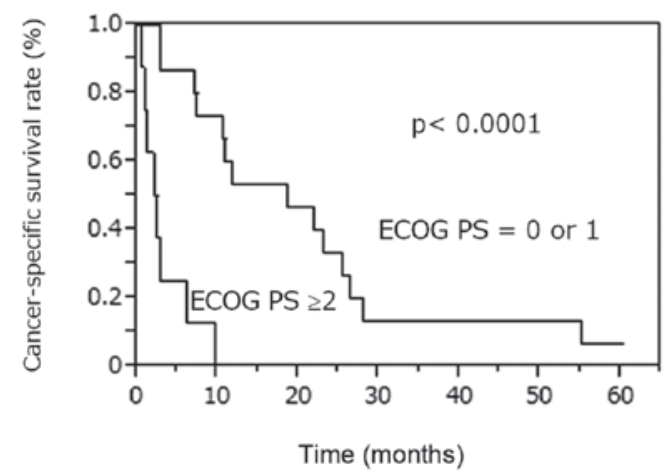

C

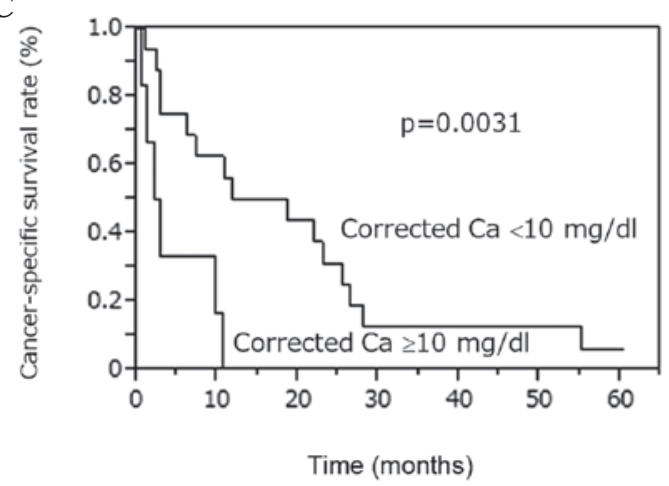

B

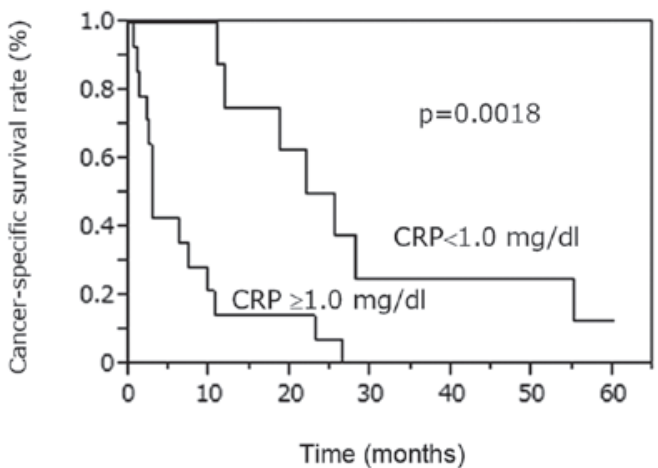

D

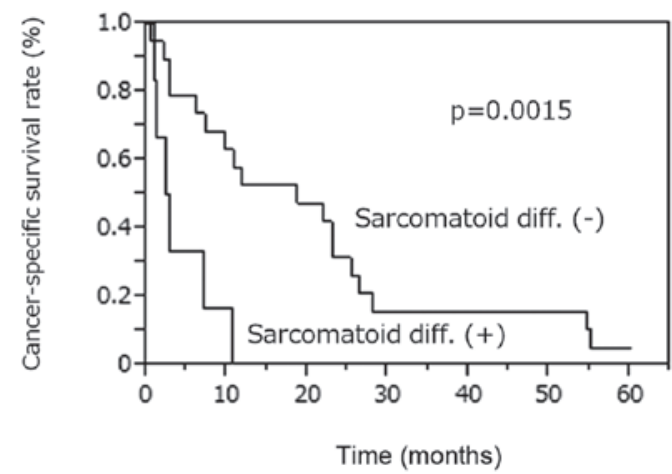

Figure 2. Cancer-specific survival rates for patients with liver metastasis from renal cell carcinoma. The Kaplan-Meier method revealed that patients with (A) ECOG PS $\geq 2$, (B) CRP level $\geq 1.0 \mathrm{mg} / \mathrm{dl}$, (C) corrected Ca level $\geq 10 \mathrm{mg} / \mathrm{dl}$ and (D) presence of sarcomatoid differentiation exhibited low cancer-specific survival rates. ECOG PS, Eastern Cooperative Oncology Group performance status; CRP, C-reactive protein; Ca, calcium.

and chest computed tomography (CT) and, if indicated, radionuclide bone scanning. LM was confirmed using $\mathrm{CT}$ or magnetic resonance imaging in all the patients. The median follow-up duration was 28.9 months (range, 2.7-180.1 months). Cancer-specific survival (CSS) was calculated from the date of $\mathrm{Nx}$ to the date of death or the date of the last follow-up. Tumor staging was performed according to the 2009 TNM classification of the Union for International Cancer Control (14). Tumor grades were assigned according to the General Rules for Clinical and Pathological Studies on Renal Cell Carcinoma in Japan (3-grade system) (15). Furmann nucleolar grading was also performed (16). This study was approved by the Ethics Committee of the National Defense Medical College (no. e-253). Consent was obtained for use of patient data.

Statistical analysis. All the calculations were performed using JMP 9.0 software for Windows (SAS Institute Inc., Cary, NC, USA). The results are expressed as means \pm standard deviation. The CSS rates were calculated using the Kaplan-Meier method and compared using the log-rank test. $\mathrm{P}<0.05$ was considered to indicate a statistically significant difference. The associations of clinicopathological parameters with death from RCC were assessed using the Cox proportional hazards regression model and summarized as hazard ratios (HRs) and 95\% confidence intervals (CIs).

\section{Results}

Patient characteristics. The clinicopathological characteristics of the patients are listed in Table I. The histopathological types were clear cell RCC in 24 cases and chromophobe RCC in 1 case. A total of 21 patients $(84 \%)$ had histological grade 3 disease, while $24(96 \%)$ had grade $\geq 3$ disease according to the Fuhrman classification. The mean age at LM diagnosis was $62.6 \pm 12.1$ years (range, 30-79 years). The interval from $\mathrm{Nx}$ to LM appearance was 38.1 \pm 55.9 months (range, 0-175.3 months) and the follow-up period between LM appearance and outcome was 16.6 \pm 17.6 months (range, 0.4-60.2 months). LM was present at the time of $\mathrm{Nx}$ in 8 and developed following $\mathrm{Nx}$ in 17 patients. The median CSS following LM diagnosis was 10.6 months. The patient survival rates at 1,2 and 3 years were 40, 24 and 12\%, respectively (Fig. 1).

Factors affecting prognosis. We next attempted to identify the clinical factors affecting the prognosis of RCC patients with LM. The Kaplan-Meier method revealed that the CSS rates were lower in patients with sarcomatoid differentiation $(\mathrm{P}=0.0015)$, ECOG PS $\geq 2(\mathrm{P}<0.0001)$, CRP levels $\geq 1.0 \mathrm{mg} / \mathrm{dl}(\mathrm{P}=0.0018)$ and corrected Ca levels $\geq 10 \mathrm{mg} / \mathrm{dl}$ ( $\mathrm{P}=0.0031$; Fig. 2). CSS was not significantly different between patients with LM at presentation and those who developed LM following $\mathrm{Nx}(\mathrm{P}=0.1102)$, between patients with LM alone and those with multiple organ metastases $(\mathrm{P}=0.0578)$, between patients who were treated with TKIs and those who were not $(\mathrm{P}=0.7848)$ and between patients who underwent hepatic resection and those who did not $(\mathrm{P}=0.0912)$ (data not shown).

Univariate analysis of clinicopathological parameters and CSS. The results of the univariate analysis for the association between clinicopathological parameters and CSS are presented 
Table II. Univariate analysis for cancer-specific survival following development of liver metastasis (LM).

\begin{tabular}{|c|c|}
\hline Clinicopathological factors & P-value \\
\hline Age $^{a}$, years $(60>$ vs. $60 \leq)$ & 0.1172 \\
\hline Sarcomatoid differentiation $^{\mathrm{b}}$ (+ vs. -) & 0.0067 \\
\hline Histological grade $3^{\mathrm{b}}$ (+ vs. -) & 0.2898 \\
\hline Fuhrman $\operatorname{grade}^{\mathrm{b}}(<3$ vs. 4$)$ & 0.4066 \\
\hline $\mathrm{MVI}^{\mathrm{b}}(+$ vs. - ) & 0.9872 \\
\hline Tumor necrosis ${ }^{\mathrm{b}}$ (+ vs. -) & 0.8618 \\
\hline Tumor size $^{\mathrm{b}}(<10$ vs. $\geq 10 \mathrm{~cm})$ & 0.9160 \\
\hline pT 1 or 2 vs. pT 3 or $4^{b}$ & 0.3196 \\
\hline Presence of LM at Nx (yes vs. no) & 0.0992 \\
\hline No. of LM at presentation (1 vs. $\geq 2$ ) & 0.4447 \\
\hline ECOG PS $^{\text {a }}(0$ or 1 vs. $2 \leq)$ & 0.0002 \\
\hline $\mathrm{CRP}^{\mathrm{a}}(<1.0 \mathrm{vs} . \geq 1.0 \mathrm{mg} / \mathrm{dl})$ & 0.0019 \\
\hline LDH $^{\mathrm{a}}$, IU/l (<338 vs. $\left.\geq 338\right)$ & 0.9019 \\
\hline Hemoglobin ${ }^{\text {a }}$ (anemia vs. normal) & 0.1704 \\
\hline Platelet count ${ }^{\mathrm{a}}\left(<35 \times 10^{4}\right.$ vs. $\left.\geq 35 \times 10^{4} / \mathrm{mm}^{3}\right)$ & 0.3434 \\
\hline Corrected calcium $^{\mathrm{a}}$ (<10 vs. $\left.\geq 10 \mathrm{mg} / \mathrm{dl}\right)$ & 0.0100 \\
\hline LM only (yes vs. no) & 0.0367 \\
\hline Tyrosine kinase inhibitors (yes vs. no) & 0.8848 \\
\hline Cytokine therapy (yes vs. no) & 0.7278 \\
\hline Local treatment (yes vs. no) & 0.8373 \\
\hline Hepatic resection (yes vs. no) & 0.0528 \\
\hline Interval from $\mathrm{Nx}$ to LM, months ( $<24 \mathrm{vs} . \geq 24)$ & 0.4218 \\
\hline \multicolumn{2}{|c|}{ 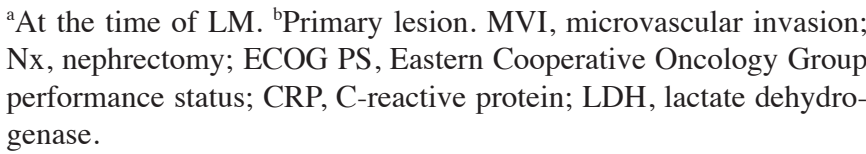 } \\
\hline
\end{tabular}

in Table II. The presence of sarcomatoid differentiation $(\mathrm{P}=0.0067)$, ECOG PS $\geq 2(\mathrm{P}=0.0002), \mathrm{CRP}$ levels $\geq 1.0 \mathrm{mg} / \mathrm{dl}$ $(\mathrm{P}=0.0019)$, corrected Ca levels $\geq 10 \mathrm{mg} / \mathrm{dl}(\mathrm{P}=0.0100)$ and presence of multiple organ metastases $(\mathrm{P}=0.0367)$ were identified as CSS predictors. The multivariate analysis (Table III) demonstrated that ECOG PS $\geq 2(\mathrm{P}=0.0063$; $\mathrm{HR}=6.46$; 95\% CI: 1.67-32.8) was an independent CSS predictor.

Patients exhibiting long-term survival following LM. The characteristics of the 9 patients who survived for $>20$ months following LM diagnosis are summarized in Table IV. The longest survival time following development of LM was 60.2 months. Two patients who received treatment with TKIs for LM survived for $\geq 23$ months. One patient remains alive after 5 years on sunitinib treatment, with prolonged stable disease. Another patient was treated with sorafenib for multiple metastases, including LM; however, the LM progressed. Two patients who received cytokine therapy for multiple organ metastases survived for $>2$ years and their tumors did not contain a high-grade component (both grade 2). Two patients who underwent hepatic resection and had no metastases to other organs survived for $\geq 22$ months and one of these two patients survived for 55.1 months. One patient who received intra-arterial injection of styrene-maleic acid neocarzinostatin
(SMANCS) and lipiodol (SMANCS/lipiodol) for LM treatment remained alive at 25.3 months. All the patients who survived for $>20$ months had ECOG PS $\leq 1$.

Outcome with local treatment for LM. The characteristics of the 9 patients who underwent local treatment for LM are summarized in Table V. In patients 1 and 3, metastases were identified only in the liver and were completely eliminated; the survival duration was 55.1 and 22 months, respectively, as described above. Three patients who received local treatments but whose ECOG PS was $>2$ only survived for a short period of time. These data suggest that local treatment may be ineffective in patients with a poor ECOG PS. Four patients undergoing local treatment survived for $>18$ months. In those patients, the number of metastatic sites (patients 1,2, 3 and 4) was relatively small. Two patients had a solitary LM, 1 had LM and local recurrence and 1 had LM, as well as lung and lymph node metastases.

\section{Discussion}

The prognosis of RCC patients with LM is extremely poor. Due to the poor prognosis, the clinical characteristics and treatment for LM have not been extensively investigated. Long-term survivors are rare among RCC patients with LM. However, it is crucial to investigate patients who have benefited from treatments such as local therapy and molecular-targeted therapy. During the cytokine era, there was no effective drug therapy for LM from RCC. TKIs are currently used for patients with metastatic RCC and patients with LM who have responded to TKIs have been reported $(10,17)$. In the present study, 9 patients (36\%) survived for $\geq 22$ months following LM diagnosis. Of those 9 patients, 5 were treated with local LM therapies or TKIs. Local treatments and TKIs appeared to improve the prognosis of some RCC patients with LM. The multivariate analysis demonstrated that only ECOG PS $\geq 2$ was an independent CSS predictor; therefore, patients with LM and ECOG PS $\geq 2$ have a poor prognosis, even if they are treated with local and/or systemic therapies, including TKIs.

In this study, we observed that the median CSS following LM appearance was 10.6 months. In previous studies, the median CSS following LM was 7.6-12.6 months (2-4), while the 1 -year survival was $38.3 \%$ (2). Those results are similar to ours. In the present study, however, we excluded patients who could not undergo $\mathrm{Nx}$ due to their deteriorated general condition caused by far-advanced disease, whereas the median CSS was only 10.6 months, indicating that the prognosis of RCC patients with LM is poor.

According to the multivariate analysis, ECOG PS $\geq 2$ at LM appearance was an independent predictor of a shorter CSS. Among RCC patients with LM, those with a poor ECOG PS only survived for a short period of time. As shown in Table V, the 3 patients with ECOG PS $\geq 2$ survived for $<3$ months following LM presentation. According to these results, all treatments appear to be ineffective for patients with ECOG $\mathrm{PS} \geq 2$.

In a proportion of patients with LM alone or a limited number of metastatic sites in addition to LM, local treatment of LM may prolong survival. We administered local treatments to 9 patients (36\%) with LM (Table V) and their median 
Table III. Univariate and multivariate analysis for cancer-specific survival following liver metastasis (LM).

\begin{tabular}{|c|c|c|c|c|}
\hline \multirow[b]{2}{*}{ Variables } & \multirow{2}{*}{$\frac{\text { Univariate }}{\text { P-value }}$} & \multicolumn{3}{|c|}{ Multivariate } \\
\hline & & P-value & Hazard ratio & $95 \%$ confidence interval \\
\hline Sarcomatoid differentiation & 0.0067 & 0.1759 & & \\
\hline ECOG PS $\geq 2^{\mathrm{a}}$ & 0.0002 & 0.0063 & 6.46 & $1.67-32.8$ \\
\hline Multiple organ metastases & 0.0367 & 0.3526 & & \\
\hline $\mathrm{CRP} \geq 1.0 \mathrm{mg} / \mathrm{dl}^{\mathrm{a}}$ & 0.0019 & 0.3704 & & \\
\hline Corrected calcium $\geq 10 \mathrm{mg} / \mathrm{dl}^{\mathrm{a}}$ & 0.0100 & 0.3339 & & \\
\hline
\end{tabular}

${ }^{\text {aAt }}$ the time of LM. ECOG PS, Eastern Cooperative Oncology Group performance status; CRP, C-reactive protein.

Table IV. Summary of the 9 cases who survived for $>20$ months following liver metastasis (LM).

\begin{tabular}{|c|c|c|c|c|c|c|c|}
\hline Case & Age $/$ gender & ECOG PS ${ }^{a}$ & $\begin{array}{c}\mathrm{CRP}^{\mathrm{a}} \\
(\mathrm{mg} / \mathrm{dl})\end{array}$ & Grade & $\begin{array}{l}\text { Other metastatic sites } \\
\text { at the time of LM }\end{array}$ & Treatment for LM & $\begin{array}{l}\text { Survival after } \\
\text { LM (months) }\end{array}$ \\
\hline 1 & 64/M & 0 & 0.3 & 3 & None & Sunitinib & 60.2 \\
\hline 2 & 61/M & 1 & 0.6 & 3 & None & Hepatic recection, $\mathrm{Nx}$ & 55.1 \\
\hline 3 & $71 / \mathrm{F}$ & NA & ND & 3 & Bone, lung & NA & 54.6 \\
\hline 4 & $54 / \mathrm{M}$ & 0 & 0.6 & 2 & $\begin{array}{l}\text { Lung, pancreas, } \\
\text { stomach, duodenum }\end{array}$ & Interferon- $\alpha$ & 28.0 \\
\hline 5 & $79 / \mathrm{M}$ & 0 & 5.9 & 2 & Lung & Interleukin-2 & 26.4 \\
\hline 6 & $77 / \mathrm{M}$ & 1 & 0.3 & 3 & LR & SMANCS/lipiodol & 25.3 \\
\hline 7 & $57 / \mathrm{F}$ & 0 & 28 & 3 & $\begin{array}{l}\text { Lung, bone, pleura, } \\
\text { LN, cerebellum }\end{array}$ & Interferon- $\alpha$, sorafenib & 23.0 \\
\hline 8 & $78 / \mathrm{M}$ & NA & ND & 3 & Lung & NA & 23.0 \\
\hline 9 & $77 / \mathrm{M}$ & 1 & 0.6 & 3 & None & Hepatic recection & 22.0 \\
\hline
\end{tabular}

${ }^{\mathrm{a}}$ At the time of LM presentation. ECOG PS, Eastern Cooperative Oncology Group performance status; CRP, C-reactive protein; M, male; F, female; Nx, nephrectomy; NA, not available; ND, not determined; LR, local reccurence; SMANCS, stylene-maleic acid neocarzinostatin; LN, lymph node.

Table V. Summary of the 9 cases who underwent local treatment for liver metastasis (LM).

\begin{tabular}{|c|c|c|c|c|c|c|}
\hline Case & Age $^{\mathrm{a}} /$ gender & No. of $\mathrm{LM}^{\mathrm{a}}$ & ECOG PS ${ }^{a}$ & Other metastatic sites & Treatment & $\begin{array}{l}\text { Survival after } \\
\text { LM (months) }\end{array}$ \\
\hline 1 & $61 / \mathrm{M}$ & 2 & 1 & None & Hepatic recection, $\mathrm{Nx}$ & 55.1 \\
\hline 2 & $77 / \mathrm{M}$ & 3 & 1 & LR & SMANCS/lipiodol & 25.3 \\
\hline 3 & $77 / \mathrm{M}$ & 1 & 0 & None & Hepatic recection & 22.0 \\
\hline 4 & 61/M & 1 & 0 & Lung, LN & $\begin{array}{l}\text { SMANCS/lipiodol } \\
\text { RFA }\end{array}$ & 18.6 \\
\hline 5 & $66 / \mathrm{M}$ & 2 & 0 & $\begin{array}{l}\text { Pancreas, kidney, } \\
\text { lung, jejunum }\end{array}$ & SMANCS/lipiodol & 11.7 \\
\hline 6 & $46 / \mathrm{M}$ & 1 & 0 & $\begin{array}{l}\text { Lung, pleura, peritoneum, } \\
\text { rib, pancreas, duodenum }\end{array}$ & TAE (lipiodol) & 7.2 \\
\hline 7 & $54 / \mathrm{M}$ & 3 & 2 & Lung, bone & RFA & 2.8 \\
\hline 8 & $45 / F$ & 1 & 2 & Lung, bone, LN & SMANCS/lipiodol & 2.3 \\
\hline 9 & 64/M & 3 & 4 & LR, iliopsoas muscle & RFA & 2.1 \\
\hline
\end{tabular}

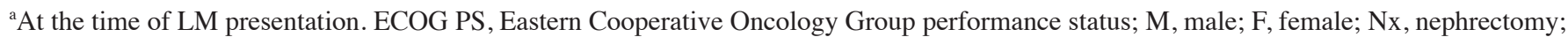
LR, local reccurence; SMANCS, stylene-maleic acid neocarzinostatin; LN, lymph node; RFA, radiofrequency ablation; TAE, transarterial embolization. 
CSS was 11.7 months. The survival duration of patients with LM alone (patients 1 and 3) and those with LM and a limited number of additional metastases (patients 2 and 4) appeared to be longer compared to that of patients with far-advanced disease. We compared patients with LM alone to those with LM and metastases to other organ(s) and observed that CSS was longer in the former (median, 38.6 months) compared to that in the latter (median, 9.7 months), with the difference being borderline significant $(\mathrm{P}=0.0578)$. Two of the 4 patients $(50 \%)$ with LM alone underwent local resection and their survival period following LM presentation was 55.1 and 22 months, respectively. LM from RCC occasionally grows rapidly and the patient's general condition deteriorates when LM becomes bulky. Therefore, local treatment of LM should be considered for patients with LM alone or those with LM and a limited number of additional metastases.

Two patients (patients 2 and 9; Table IV) survived for $>20$ months following hepatic resection for LM. Staehler et al (13) reported that the overall survival of RCC patients with LM alone who underwent hepatic resection was longer than that of those who did not undergo hepatic resection. Therefore, in RCC patients with LM alone, prognosis may be improved by hepatic resection. Furthermore, it was reported that in RCC patients, metachronous hepatic resection for LM prolonged overall survival compared to synchronous hepatic resection (18). Based on those reports, aggressive hepatic resection should be recommended if a radiological cancer-free status is achieved.

In the present study, the 2 patients who were treated with TKIs survived for $>20$ months. TKIs were used by 6 of the 25 patients (24\%) following LM diagnosis. CSS was not significantly different between patients treated with TKIs and those who were not. However, 1 patient (case 1 in Table IV) appeared to benefit from TKI treatment, with the size of the LM remaining stable for 5 years. In the 2 patients who were treated with TKIs and survived for $>20$ months, ECOG PS was 0 . A proportion of RCC patients with LM may indeed benefit from TKI treatment. Therefore, in patients with an ECOG PS of $<1$, TKI treatment may be a viable option.

Two patients received cytokine therapy for multiple metastases, including LM, and survived for $>26$ months. However, such patients are a rare finding. The histological grade of the primary lesions in those 2 patients was 2 (3-grade system), without a high-grade component. As the growth rate of the metastatic lesions is likely to be slow, such patients may survive over a long period of time on cytokine therapy alone.

There were several limitations to this study. First, this was a retrospective study conducted at a single institution with a small number of RCC patients with LM. LM is relatively rare in patients with RCC and it is difficult to collect a sufficient sample size at a single institution. Therefore, a multi-institutional joint study is required to verify our findings. Second, this study excluded patients who did not undergo Nx. There were certain patients with far-advanced RCC and LM who survived for only a short period of time. In addition, the efficacy of molecular-targeted therapies, including TKIs, for such patients mus be evaluated in the future. However, despite these limitations, our study may have generated useful clinical data on this understudied type of cancer.
In conclusion, RCC patients with LM may benefit from local treatment of LM, such as surgical resection, if they have a limited number of metastatic sites in addition to LM and if their ECOG PS is favorable and stable. Indeed, a proportion of RCC patients with LM benefit from TKI therapy. By contrast, RCC patients with LM and an ECOG PS $\geq 2$ appear to have a poor prognosis, regardless of any local or systemic treatment.

\section{References}

1. Linehan WM, Walther MM, Alexander RB and Rosenberg SA: Adoptive immunotherapy of renal cell carcinoma: studies from the Surgery Branch, National Cancer Institute. Semin Urol 11: 41-43, 1993.

2. Naito S, Yamamoto N, Takayama T, et al: Prognosis of Japanese metastatic renal cell carcinoma patients in the cytokine era: a cooperative group report of 1463 patients. Eur Urol 57: 317-325, 2010.

3. Shinohara N, Nonomura K, Abe T, et al: A new prognostic classification for overall survival in Asian patients with previously untreated metastatic renal cell carcinoma. Cancer Sci 103: 1695-1700, 2012

4. Motzer RJ, Bacik J, Murphy BA, Russo P and Mazumdar M: Interferon-alfa as a comparative treatment for clinical trials of new therapies against advanced renal cell carcinoma. J Clin Oncol 20: 289-296, 2002.

5. Leibovich BC, Cheville JC, Lohse CM, et al: A scoring algorithm to predict survival for patients with metastatic clear cell renal cell carcinoma: a stratification tool for prospective clinical trials. J Urol 174: 1759-1763, 2005.

6. Shuto T, Inomori S, Fujino $\mathrm{H}$ and Nagano $\mathrm{H}$ : Gamma knife surgery for metastatic brain tumors from renal cell carcinoma. J Neurosurg 105: 555-560, 2006.

7. Toyoda Y, Shinohara N, Harabayashi T, et al: Survival and prognostic classification of patients with metastatic renal cell carcinoma of bone. Eur Urol 52: 163-168, 2007.

8. Yasuda Y, Fujii Y, Yuasa T, et al: Possible improvement of survival with use of zoledronic acid in patients with bone metastases from renal cell carcinoma. Int J Clin Oncol 18: 877-883, 2013.

9. Hoshi S, Jokura H, Nakamura H, et al: Gamma-knife radiosurgery for brain metastasis of renal cell carcinoma: results in 42 patients. Int J Urol 9: 618-627, 2002.

10. Zeng H, Li X, Yao J, et al: Multifocal brain metastases in clear cell renal cell carcinoma with complete response to sunitinib. Urol Int 83: 482-485, 2009.

11. Molina AM, Ginsberg MS and Motzer RJ: Long-term response with everolimus for metastatic renal cell carcinoma refractory to sunitinib. Med Oncol 28: 1527-1529, 2011.

12. Alves A, Adam R, Majno P, et al: Hepatic resection for metastatic renal tumors: is it worthwhile? Ann Surg Oncol 10: 705-710, 2003.

13. Staehler MD, Kruse J, Haseke N, et al: Liver resection for metastatic disease prolongs survival in renal cell carcinoma: 12 -year results from a retrospective comparative analysis. World J Urol 28: 543-547, 2010.

14. Sobin LH, Gospodarowicz MK and Wittekind Ch (eds): TNM classification of Malignant Tumors. 7th edition. Wiley-Blackwell, West Sussex, UK, 2009.

15. Ito K, Yoshii H, Asakuma J, et al: Clinical impact of the presence of the worst nucleolar grade in renal cell carcinoma specimens. Jpn J Clin Oncol 39: 588-594, 2009.

16. Fuhrman SA, Lasky LC and Limas C: Prognostic significance of morphologic paramaters in renal cell carcinoma. Am J Surg Pathol 6: 655-663, 1982.

17. Gore ME, Hariharan S, Porta C, et al: Sunitinib in metastatic renal cell carcinoma patients with brain metastases. Cancer 117: 501-509, 2011.

18. Langan RC, Ripley RT, Davis JL, et al: Liver directed therapy for renal cell carcinoma. J Cancer 3: 184-190, 2012. 